\title{
Lectura Musical en el ámbito digital; aplicaciones para tablets
}

\section{Music Reading in Digital Environments; Apps for Tablets}

\author{
Javier Félix Merchán Sánchez-Jara
}

GIR E-LECTRA Edición, Electrónica y Lecto-escritura Digital, Universidad de Salamanca, España. javimusicman@hotmail.com

\section{Resumen}

La lectura musical permite, a través de distintos procesos, habilidades adquiridas y experiencias previas, la recreación o interpretación del mensaje musical previamente codificado mediante cualquiera de los distintos sistemas de notación disponibles. De igual manera, mediante la lectura musical el músico experimentado es capaz de generar imágenes sonoras a nivel interno que permiten la representación silenciosa del mensaje cifrado. Se analizan las características y los procesos más genéricos dentro de la lectura musical, las formas y aplicaciones más comunes de estos modelos de lectura y se describen brevemente los sistemas de notación y los códigos más utilizados. En una segunda parte se analiza el desarrollo y uso de las nuevas aplicaciones para la lectura musical en dispositivos electrónicos. Se estudia el desarrollo y la penetración en la comunidad musical de este tipo de herramientas; la clasificación, tipologías más generalizadas y se refieren las características y funcionalidades básicas de las aplicaciones más representativas en torno a criterios como el ámbito y contexto de uso, la distribución por instrumentos y/o estilos musicales, plataformas, sistemas operativos o formatos. Se analizan, de igual manera, algunas soluciones desarrolladas para problemas históricos dentro de la lectura musical, como el paso de página.

\section{Palabras clave}

Lectura musical; notación musical; aplicaciones para lectura musical; lectura electrónica.

\begin{abstract}
Reading music allows, through different processes, learnt abilities and previous experiences, for the recreation or interpretation of the musical message which had been previously coded using one of the many notation systems available. In the same way, reading music enables the experienced musician to generate musical images internally, which silently represent the coded message.

The most generic processes and characteristics amongst musical reading will be analysed, along with the most common forms and applications of these reading models and the most widely used codes and notation systems. In the second part, the development and use of new tecnologies for reading music in electronic devices are described and the penetration of these tools in the musical community analysed and classified, bearing in mind the most common types and functions and the characteristics and basic functionalities of the most representative applications. Some solutions, developed in order to deal with historical problems within the reading of music, such as the turning over of the page, are also considered.
\end{abstract}

\section{Keywords}

Music reading; Music notation; Music reader; Electronic reading. 


\section{Introducción}

La lectura musical como proceso de codificación/decodificación de una estructura formal, compuesta por símbolos y grafías pertenecientes a un sistema de notación específico, que en su uso más generalizado pretende la recreación de la obra musical, mediante la interpretación vocal o instrumental, incorpora la necesidad de poseer ciertas competencias básicas relacionadas con dos aspectos claramente delimitados; La habilidad de la lectura per se, como proceso de decodificación de la notación expresada, y por otro, la serie de competencias o habilidades mecánicas o motoras presentes en los procesos mediante los cuales se traslada al instrumento la información previamente decodificada. En este sentido están implicados de manera necesaria sistemas de gobierno que permiten la coordinación entre los procesos visuales, cognitivos y motores (Gudmundsdottir, 2010).

Así, de esta manera, y en relación a lo anteriormente expuesto, podemos proponer una primera aproximación al concepto de lectura musical, en relación al conjunto de actividades y condiciones necesarias para la construcción sistemática de procesos que permiten la percepción y recreación del mensaje musical codificado (Sloboda, 2005).

El elemento esencial que actúa como nexo o vínculo entre la intención artística primigenia del creador (compositor), y la recreación o representación final del mensaje musical por parte del intérprete, es la partitura ${ }^{1}$ o texto musical. Este pretende plasmar, mediante un conjunto de símbolos normalizados, el mensaje musical que el creador desea trasmitir, de manera que este se reproduce con la intención originaria, mediante la interpretación y decodificación del mismo por parte del intérprete, a través de cualquier instrumento musical o de la propia voz. Estos procesos de codificación/decodificación del mensaje musical implican necesariamente un código estructurado y normalizado de símbolos (que puede variar sensiblemente según el instrumento o estilo musical), y un soporte que permita su fijación estable y permanente. La utilización de según qué soporte o formato ha variado sustancialmente a lo largo de la historia, persiguiendo, en cualquier caso, la adaptación óptima del mensaje fijado, a las necesidades específicas que su uso y lectura requieren.

La última expresión de estas evoluciones, encaminadas a lograr la plena integración entre contenido y soporte, en relación al elevado conjunto de usos y necesidades específicas de los mismos, viene representada por los textos musicales en formato electrónico. Estos incorporan una serie de herramientas que modifican sustancialmente la idea preconcebida de considerar las partituras como objetos estáticos que no permiten ninguna interacción ni modificación del mensaje implícito, más allá

Aunque el término partitura refiere una forma específica de codificación del mensaje musical a nivel formal, estructural y de notación, su uso estereotipado permite referirnos a ella como texto musical de forma genérica, independientemente de la forma o el sistema de notación. 
de la interpretación personal que el músico (interprete) establece tras el propio acto de decodificación. Las nuevas herramientas surgidas a partir de la integración de estas nuevas tecnologías permiten, al contrario, adaptar el texto a las características propias del instrumento; conformar cualquiera de los elementos nucleares del mismo (altura musical/entonación y ritmo) a cualquier situación concreta, o modificar su estructura en torno a la disposición o presentación del mismo, según requerimientos contextuales.

Todo este conjunto de avances y nuevas posibilidades permiten, en definitiva, que en cualquier circunstancia imaginable, la función de intermediación que el intérprete ejerce entre la idea original del compositor y la percepción final del mensaje musical, se desarrolle de la manera más conveniente, adaptada y natural posible; y lo que es más importante, que el texto como vehículo de trasmisión se adapte de manera más específica y pormenorizada a los requerimientos propios del estilo, el instrumento o la obra en sí.

\section{Lectura musical}

A pesar de que la concreción de un concepto como el de lectura musical es una tarea difícil de llevar a cabo, como consecuencia de su naturaleza eminentemente abstracta y de la cantidad de circunstancias y características implicadas, podemos definirla de manera genérica como el conjunto de procesos de codificación/decodificación e interpretación del texto musical; entendido este como sistema estructurado y normalizado, de carácter simbólico, que representa sonidos y sus atributos con el fin de evocar mentalmente, o de reproducir mediante la voz o un instrumento musical, una idea u obra musical previamente creadas y escritas.

Generalmente el uso principal de la lectura musical es la interpretación de una obra musical creada de manera previa. No obstante, se consideran de igual manera otros objetivos no menos importantes y habituales como son el estudio o el análisis musical, entre otros.

Aunque son muchos los procesos, requerimientos y condicionantes que afectan a todos los procesos relacionados con la interpretación de textos musicales, a nivel genérico, la lectura musical implica la activación de mecanismos que permiten establecer relaciones entre la información codificada y el conocimiento gramatical de la música (ritmo, altura musical, armonía, timbre, intensidad, etc.) adquirido y asimilado en experiencias previas.

En este sentido, tanto el grado de experiencia del lector como de conocimiento a nivel teórico, armónico o formal, condiciona en gran medida tanto alguno de los usos propios de la lectura musical, como la validez de sus respuestas. 


\subsection{Tipología de la lectura musical. Lectura musical según la respuesta o salida}

Generalmente este es uno de los criterios más obvios y naturales a la hora de clasificar los tipos y usos de la lectura musical, toda vez que se relaciona con la intención y uso que más la afecta y que le es más propio; la de recrear en forma de imágenes sonoras (Brodsky, Kessler, Rubinstein, Ginsborg, \& Henik, 2008) o mediante estímulos perceptibles por el oído como recreación de la obra o el texto musical escrito.

\subsubsection{Lectura silenciosa}

La denominada lectura silenciosa representa todos los procesos de codificación/decodificación e interpretación del texto musical, que son realizados de manera individual e interna, y sin que se produzca ninguna respuesta física (vocal o instrumental) de recreación sonora (estímulo auditivo a nivel físico) de la idea o de la obra representada. De manera general, el procesamiento de la información en estos casos conduce a la representación mental de la idea musical y a la evocación de imágenes sonoras, como otra forma de recreación del contenido semántico del mensaje.

Las imágenes sonoras guardan relación con los procesos de audición interna también denominados audición notacional (Brodsky et al., 2008) y que grosso modo, consiste en la recreación o evocación a nivel mental del discurso musical explicitado en el texto. Estas imágenes sonoras pueden guardar mayor o menor relación de exactitud o fidelidad con el mensaje musical representado, este tipo especial de relación es referida por algunos autores como analogía semántica (Galera \& Gim, 2012), dependiendo este hecho en gran medida de las habilidades del lector, y sobre todo del nivel de experiencias previas y del conocimiento de la teoría y gramática musical.

\subsubsection{Lectura sonora}

De forma complementaria a la tipología referida anteriormente, podemos considerar como tipos de lectura sonora todos aquellos procesos que persiguen la recreación e interpretación de la idea musical codificada mediante la producción de los pertinentes eventos sonoros que posibilitan la percepción del mensaje musical de la misma forma, y con la misma intención primitiva que el autor propone en el momento de su creación. Generalmente, la recreación sonora a nivel físico o acústico del mensaje codificado se materializa a través de la ejecución vocal o instrumental, bien sea en ejecuciones de intérpretes como agente individual, o formando parte de conjuntos instrumentales o vocales más extensos (coros, orquestas, grupos de cámara, bandas, etc.). 


\subsubsection{Interpretación instrumental}

La lectura musical como herramienta o conjunto de procesos dirigidos a la interpretación instrumental implica que el contenido semántico que incorpora el mensaje codificado es traducido mediante diferentes procesos a nivel cognitivo, (que requieren de manera vinculante del conocimiento previo de la técnica y mecánica instrumental), en las directrices y órdenes motoras que permiten la reproducción musical a través del propio instrumento (Kinsler, V. \& Carpenter, R. H., 1995). En este sentido, se produce un doble proceso de codificación/decodificación, a nivel semántico, y a nivel de los procesos motores que se relacionan con la mecánica propia de la ejecución instrumental.

Estos procesos cognitivos de codificación/decodificación actúan a modo de interfaz entre el estímulo visual y la acción motora sobre el instrumento, y son los responsables del retardo o delay entre la visualización y reconocimiento del texto (estímulo visual) y los procesos motores responsables de la producción sonora (Sloboda, 2005). Para minimizar estos efectos, los músicos más experimentados suelen fijar la vista en un número determinado de notas por delante de la nota que se está ejecutando. La diferencia espacial entre la nota ejecutada o cantada y la nota leída varía sustancialmente en virtud de la experiencia, los conocimientos y la propia habilidad del ejecutante.

La figura 1 muestra cómo en los músicos con mayor experiencia lectora, el estímulo visual y la posición del ojo se encuentra uno o dos compases por delante de las notas que en ese momento están siendo ejecutadas y reproducidas sonoramente.

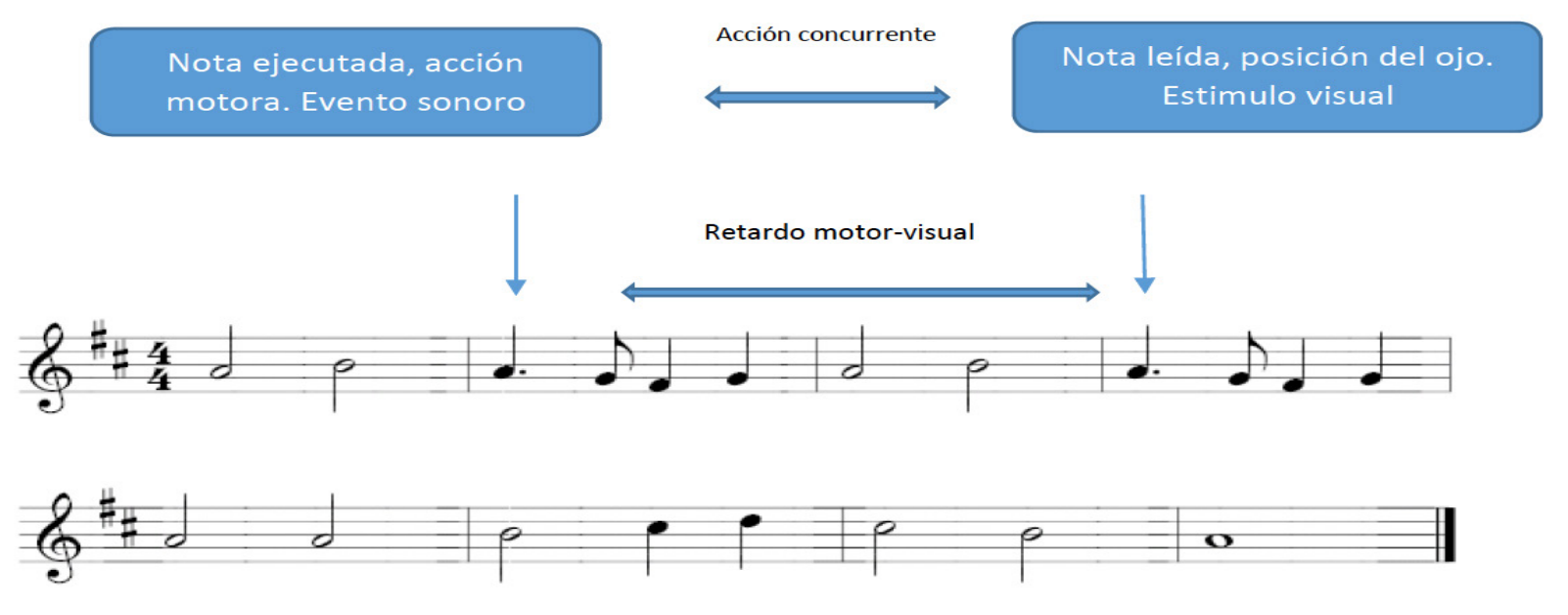

Figura 1. Ejemplo de representación de la diferencia espacial entre la nota ejecutada y la posición de la vista durante la interpretación. Fuente. Elaboración propia.

\subsubsection{Interpretación vocal}

En los procesos de lectura musical dirigidos o relacionados con la interpretación vocal, juega un papel primordial la capacidad de relacionar los estímulos visuales con la evocación de imágenes sonoras 
(percepción interna de sonidos en ausencia de estímulo físico-auditivos), y con la identificación y recuperación de las diferentes alturas musicales y relaciones interválicas de la denominada memoria tonal o pitch memory (Schön \& Besson, 2002). En este sentido, la lectura relacionada con la recreación del texto musical mediante la interpretación vocal, se estructura en torno al conjunto de procesos mediante los cuales el estímulo visual activa ciertas etiquetas asociadas a determinados sonidos, o estructuras melódicas concretas, almacenados en la citada memoria tonal.

Las personas con oído absoluto ${ }^{2}$ no requieren de la misma manera del uso de la memoria tonal y de las relaciones interválicas, toda vez que son capaces de identificar y/o producir cualquier altura musical en ausencia de ningún marco referencial. Esta identificación, por lo tanto, se produce como recuperación directa de la memoria musical, y no como comparación con ningún sonido que actúe como referencia.

$2 \quad$ Habilidad inherente de forma innata a ciertas personas para identificar cualquier sonido musical mediante su nombre y altura relativa, sin necesidad de referencias externas en relación con su tesitura o contexto.

\subsubsection{Interpretación verbalizada}

La interpretación verbalizada de un texto musical incorpora, a nivel general, muchos de los procesos que se desarrollan en la interpretación vocal, con la salvedad (muy significativa por otra parte), de que no requiere la identificación de la altura musical de los sonidos. Este hecho obedece a que la característica más definitoria de este tipo de lectura musical no es reproducir el mensaje musical como tal ${ }^{3}$, (discurso compuesto de sonidos con distintas alturas musicales que trascurren en relación a una serie de estructuras rítmicas), sino que constituye una forma de reproducir el código escrito en relación al nombre arbitrario que representa a cada nota (Do, Re, Mi, Fa... etc.).

Este tipo de lectura se conoce de igual manera como lectura rítmica o solfeo rítmico, y es muy común en la práctica y entrenamiento de cualquier tipo de músico que utilice los sistemas de notación clásicos.

\subsection{Lectura musical según el grado de conocimiento previo del texto}

El grado de conocimiento previo del texto conforma otro de los criterios más señalados para la clasificación y subdivisión de los distintos tipos de lectura. A diferencia de otras formas de lectura, la lectura musical implica, al margen de la decodificación semántica del texto, una nueva codificación a nivel de la mecánica y al técnica instrumental o vocal; es precisamente esta fase la que precisa del conocimiento y/o estudio previo del texto. No obstante, los músicos más expertos son capaces de realizar ambos procesos a tiempo real sin la existencia de contacto previo con la representación textual de la obra. 


\subsubsection{Lectura a primera vista}

La lectura musical a primera vista, repentización o sight-reading ${ }^{4}$, generalmente se relaciona con los procesos de lectura sonora y dentro de la interpretación vocal o instrumental. En estos procesos la decodificación semántica y la codificación relacionada con la mecánica y la ejecución instrumental se realizan de manera simultánea y sin conocimiento previo del texto musical, de manera que los estímulos visuales se traducen en acciones motoras sobre el instrumento de manera concurrente (Waters, Underwood, \& Findlay, 1997). Aunque el entrenamiento y la experiencia previa, (y sobre todo un gran dominio del instrumento), permiten que la diferencia espacio-temporal entre el estímulo visual y la respuesta motora se reduzca al mínimo, los procesos de codificación y decodificación son realizados igualmente de manera simultánea, por lo que para que el discurso musical fluya es necesario fijar la vista sobre el texto algunos compases o algunas notas por delante de la nota que se está ejecutando, tal y como observamos con anterioridad.

$4 \quad$ Otras formas de expresión incluyen términos como repentización o primera lectura.

\subsubsection{Lectura como guía}

La lectura musical puede actuar en otros casos como puntos de acceso o estímulos que guían y propician la recuperación de las estructuras aprendidas y almacenadas en la memoria a largo plazo; para ello es necesario un análisis y estudio previo de forma minuciosa que permita por un lado almacenar en la citada memoria a largo plazo la serie de secuencias estudiadas que componen el discurso musical implícito en el texto, y por otro relacionarlo y fijarlo a nivel visual, de manera que es el propio estímulo visual el que establece conexión con la secuencia o pasaje aprendido. Generalmente el uso de este tipo de lectura permite al interprete concentrase en la ejecución musical al tiempo que dispone de una guía en la interpretación que aporta seguridad y confianza, sobre todo en relación a obras muy largas o complejas.

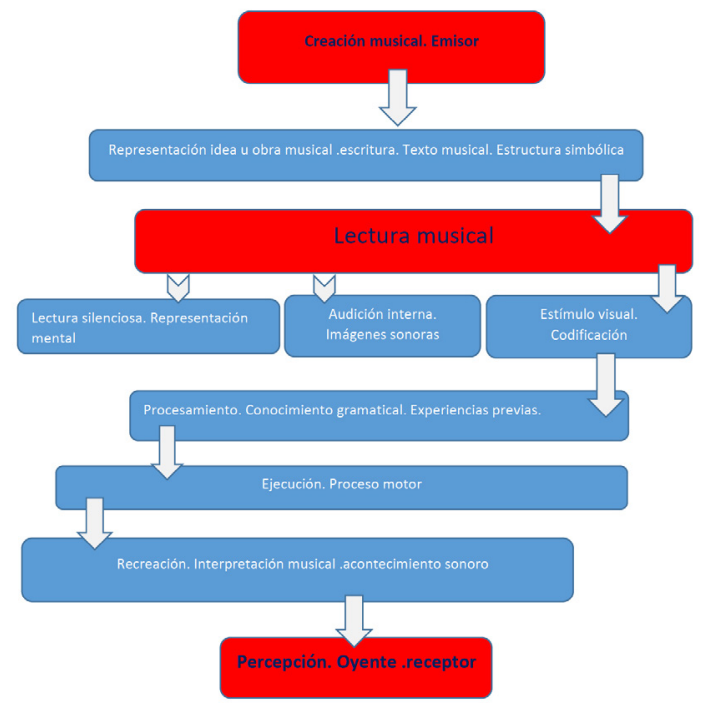




\section{Sistemas de notación}

Los sistemas de notación musical permiten la codificación semántica del mensaje musical en un sistema estructurado y normalizado de símbolos y grafías que permiten la representación o la recreación sonora de la obra musical a nivel textual. Los sistemas de notación incorporan un conjunto más o menos amplio de símbolos genéricos, relacionados con los atributos esenciales de los sonidos musicales, y que pueden ser combinados mediante una sintaxis precisa, pero muy flexible, de manera que se posibilita la representación de cualquier idea u obra musical por compleja que esta sea. Dentro del conjunto general de símbolos y grafías, se establecen un número de subconjuntos que agrupan elementos que hacen referencia a características específicas de determinados aspectos como la ejecución musical y con las particularidades del estilo, el instrumento o la época.

De forma genérica, la notación musical incluye elementos que permiten expresar la altura del sonido, su duración y una serie de atributos expresivos relacionados con la intensidad, el timbre, u otros matices (Read, 1982).

\subsection{Evolución}

Los sistemas de notación musical han evolucionad a lo largo de los siglos con el fin de sistematizar un conjunto concreto de símbolos y grafismos, relacionados mediante una sintaxis formalizada, que puedan representar de una manera fiel, operativa e intuitiva toda la casuística (a priori infinita) que puede concurrir en un texto musical u obra musical.

Esta evolución ha transitado de la utilización de letras del abecedario como representación de las diferentes alturas musicales (Antigua Grecia), pasando por la representación de las fluctuaciones o giros melódicos mediante símbolos que emulan los cambios de dirección de la misma, hasta los actuales sistemas de notación referenciados a un espacio bidimensional como es el pentagrama. Otros sistemas incorporan mecanismos que permiten representar el texto musical en relación a la manera en que el mensaje se ejecuta en el instrumento; de manera que los sonidos son representados mediante la localización espacial dentro de un sistema tabulado que representa los trastes o las teclas de los instrumentos a los que refiere.

En la actualidad, y al margen de las variaciones idiomáticas existentes, se ha consolidado como sistema universal el basado en la representación simbólica de los sonidos y sus atributos, a través la combinación de elementos que representan la altura y la duración sobre un espacio que los referencia; el pentagrama. 


\subsection{Sistemas idiomáticos. Sistemas de notación espacial. Tablaturas}

Los sistemas basados en tablatura, desarrollados en un principio para instrumentos de cuerda y de tecla (s. XVI), se siguen empleando en la actualidad con gran profusión para toda la familia de instrumentos de cuerda y temperado mediante trastes (fretted instruments). Estos sistemas cuentan entre sus bondades, la capacidad de indicar al intérprete el lugar topográfico exacto donde se produce la nota representada, deshaciendo la ambigüedad que se produce en algunos instrumentos (la guitarra, por ejemplo) donde un mismo sonido musical puede producirse de dos o más ubicaciones diferentes en el diapasón.

Esta cualidad expresa, además, de manera implícita, la forma y manera en la que el compositor o el trascriptor entienden que la obra debería ser ejecutada a nivel técnico o de digitación. Por todo ello su lectura y compresión es mucho más intuitiva que los sistemas basados en símbolos, y no requieren, de manera taxativa, de un conocimiento ni entrenamiento previo del sistema tan profundo como estos últimos.

Por el contrario, los sistemas de tablatura incorporan ciertas limitaciones para expresar la duración de las notas (sobre todo en textos polifónicos), y las estructuras y patrones rítmicos incorporados se perciben de manera menos precisa, y con cierta ambigüedad (Tonazzi, 1996). Además, las relaciones interválicas entre las diferentes notas no quedan explicitadas de manera visual. Otro de los grandes inconvenientes refiere el hecho de que estos sistemas en la actualidad están muy enfocados a resolver las particularidades propias de ciertos instrumentos, y en relación con ciertos estilos, por lo que no son exportables ni generalizables a otros ámbitos organológicos ni estilísticos.

\subsection{Sistemas de notación textuales}

Los sistemas de notación textual se desarrollan, a diferencia de los sistemas tabulados, mediante la combinación, según una serie de reglas preestablecidas (sintaxis), de los elementos y símbolos gramaticales, que representan los sonidos y sus atributos, sobre un espacio de referencia denominado pentagrama. Este espacio se dispone de forma axial en dos dimensiones que guardan relación directa con los atributos principales del sonido musical; la altura y el tiempo.

\subsubsection{Elementos contextuales}

Los elementos contextuales están constituidos por un número delimitado de símbolos configurados de manera predeterminada, que afectan de manera global a todo el texto musical, y que contextualizan la obra en un marco harmónico, rítmico, de carácter, o estilístico. 


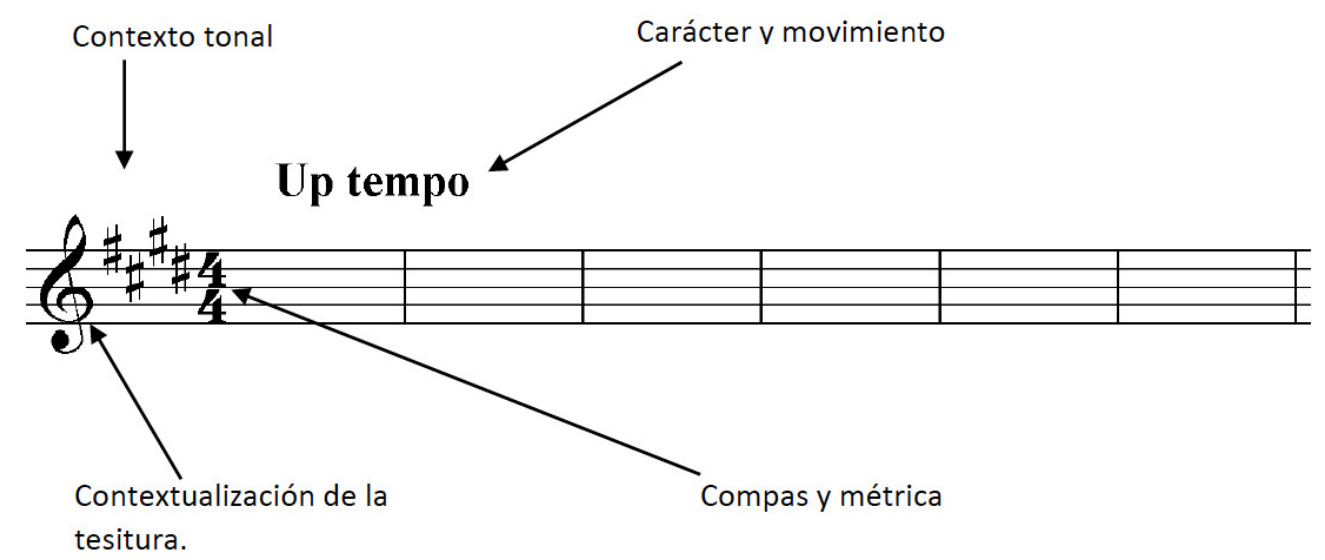

Figura 3. Identificación de los elementos contextuales. Fuente: Elaboración propia.

\subsubsection{Elementos constitutivos del lenguaje musical}

Los elementos constitutivos a partir de los cuales se forma cualquier texto musical, representan atributos del sonido relacionados con las principales características que los definen: altura musical (frecuencia), duración e intensidad.

Altura. La altura musical se representa mediante las distintas localizaciones que la nota musical ${ }^{5}$ puede adoptar en el eje vertical (imaginario) en torno al cual se estructura el pentagrama. La altura real del sonido representado, a nivel físico-acústico, vendrá condicionada por el contexto general del texto en relación a la tesitura o la clave en el que esté expresado.

Duración. La duración de la nota musical, por el contrario, guarda relación a nivel parcial con el eje horizontal del pentagrama que representa la evolución del pulso de la obra y por ende el paso del tiempo (Gould, 2011). En cualquier caso la notación existente y más generalizada permite establecer y representar distintos valores de duración del sonido únicamente a través de símbolos concretos (figuras redondas, blancas, negras, etc.) sin necesidad de referenciarlo a ningún tipo de evolución en el eje horizontal.

\section{Aplicaciones para la lectura musical en dispositivos electrónicos; Music Readers}

Los Music Readers son las aplicaciones desarrolladas para dispositivos electrónicos móviles o de sobremesa que permiten la lectura, edición, y gestión de obras musicales de manera especializada, y representadas en diferentes sistemas de notación y soportadas en diferentes formatos.

En los últimos años, y en base a la gran aceptación y penetración que estas nuevas tecnologías han 
tenido dentro del colectivo musical (tanto en los ámbitos de la música clásica, como de la música moderna) las diferentes aplicaciones se han ido especializando y desarrollando en función de criterios como el género musical, el instrumento, el uso o el contexto al cual están orientadas, permitiendo la determinación de las funciones y herramientas en torno a estos criterios.

De manera general, y al margen de otras muchas bondades relacionadas con cuestiones más específicas, las aplicaciones para la lectura musical (Music-readers), solucionan prácticamente la totalidad de los problemas relacionados con la disponibilidad, acceso, ubicuidad, y volumen de la información, o con la organización, gestión o edición de las colecciones que albergan o manejan. Este tipo de prestaciones están disponibles en la mayor parte (por no decir todas) de las aplicaciones de la misma manera o similar que lo hacen sus hermanas las e-readers.

Las aplicaciones de lectura musical permiten el acceso a los contenidos mediante cualquiera de los métodos característicos a este tipo de dispositivos; mediante los distintos recursos disponibles por medio de tecnología web, bien sea a través de servidores basados en tecnología cloud, a través de bases de datos colaborativas en las que los usuarios comparten sus propios documentos y contenidos, o mediante los distintos canales de comercialización disponibles específicos para este tipo de recursos. Además, permiten el acceso directo a la colección personal a través de la biblioteca electrónica incorporada en el propio dispositivo. Más allá de los métodos de incorporación anteriormente citados, podemos ingresar archivos a nuestra biblioteca a través del scanner incorporado en la mayoría de las aplicaciones, el cual nos permite la digitalización e incorporación a la biblioteca de cualquier obra musical disponible o accesible en formato papel.

Las aplicaciones más modernas incorporan también sistemas que permiten la comunicación y sincronización entre diferentes dispositivos, posibilitando una serie de funciones muy interesantes para la organización y gestión de grupos instrumentales o vocales.

\subsection{Biblioteca electrónica}

Los dispositivos electrónicos más comunes en la actualidad permiten asociar bibliotecas electrónicas con las distintas aplicaciones disponibles para su gestión. En el caso de las aplicaciones para lectura musical esta consideración es de vital importancia, al ser la gestión (a nivel indización y recuperación) de la propia biblioteca una de las funcionalidades más relevantes dentro de la gestión de colecciones musicales. La incorporación de estos espacios en el sistema permite, entre otras muchas funciones, la organización, clasificación y recuperación de los documentos mediante puntos de acceso configurables. De forma genérica se establecen, por defecto, algunos de los más comunes a todo tipo de colecciones como son el título de la obra, el autor o autores, el género musical, la dificultad técnica o la valoración personal que el propio usuario puede referir de la misma. 
De igual manera, en la mayoría de las aplicaciones, están disponibles una serie de campos para la asignación de metadatos que permiten, por ejemplo, asociar cualquier tipo de descriptores libres a los aspectos o criterios relativos a la indización y recuperación que más interesa al usuario, como la tonalidad, versión y/o edición, tempo, tesitura, carácter, agrupación instrumental, etc. Esta posibilidad resulta de gran utilidad para la recuperación de obras, en estilos en los que existe una gran variedad de versiones de un mismo tema editados o pertenecientes a distintas obras de carácter recapitulativo; la gestión y recuperación de obras o fragmentos musicales en obras como los Real Book de Jazz o Blues son algunas de las funciones susceptibles de representar el gran potencial que estas herramientas ofrecen al usuario.

Además, es posible la asignación y edición conjunta de metadatos asociados a cualquier grupo de archivos, pudiendo ser asignados a cualquier subconjunto de obras o archivos que comparten una o varias cualidades o características, dentro del conjunto general de la colección. Algunas de las características comunes más presentes dentro de las colecciones de obras musicales son la pertenencia a la misma obra recapitulativa, edición, trascriptor, instrumento o familia de instrumentos, tonalidad, estilos o géneros, etc.

\subsubsection{Creación, edición y gestión de Set-Lists}

Un Set-List es un documento con forma de lista que relaciona un conjunto de obras musicales agrupadas en torno a criterios relativos al orden de interpretación de las mismas, generalmente vinculados a un evento en concreto o a programas y repertorios consolidados que se representan con cierta frecuencia o asiduidad. El criterio básico para la confección de estos set-list normalmente hace referencia al orden secuencial de ejecución de las obras en la actuación. Las aplicaciones para la lectura electrónica permiten crear set-list personalizados para cada actuación o ensayo, vinculando cada lista con eventos marcados en el calendario; además permite compartirlos y gestionarlo entre dispositivos vinculados de manera que cada miembro de un conjunto instrumental puede tener actualizado cualquier cambio o edición que los responsables del mismo introduzcan en este. Por otro lado los set-list electrónicos son objetos dinámicos que interactúan en el momento del evento permitiendo la recuperación automática de una obra en el momento que finaliza la ejecución de la que la precede.

\subsection{Edición y notación}

Los music readers incorporan de manera generalizada una serie de herramientas muy potentes para la notación y la edición del texto musical, independientemente del sistema de notación empleado o del formato que los soporta. Entre las muchas opciones disponibles en este ámbito, los músicos cuentan con la posibilidad de deshacer los cambios efectuados, o de almacenar en la biblioteca una 
copia del texto original y otra con las anotaciones o ediciones efectuadas. Esta característica resulta muy interesante toda vez que es práctica común entre los músicos la constante modificación del texto en las sesiones de estudio o ensayo; pudiéndose conservar en todos los casos una copia limpia del texto en cuestión.

Algunas aplicaciones más específicas incorporan la posibilidad de la edición o escritura mediante programas desarrollados específicamente para estos fines. Estas incorporan, entre otras muchas, la posibilidad de reproducir, mediante sonidos sintetizados, el texto escrito o editado. En la mayoría de los casos se dispone de una amplia paleta de caracteres tipográficos específicos para cada sistema de notación, configurables en tamaño, fuente o color, y se permite además la sincronización de los cambios realizados en el documento entre dispositivos vinculados, permitiendo la edición conjunta para obras relacionadas con conjuntos instrumentales o vocales.

\subsection{Asociación y alojamiento de objetos multimedia}

La posibilidad de asociar objetos y recursos de diversa índole a los archivos almacenados en la biblioteca electrónica representa una de las funcionalidades con mayor potencial para el músico que ofrecen las aplicaciones de lectura musical. De esta manera podemos disponer de recursos de referencia como los diccionarios de escalas o acordes que permiten observar la estructura armónica, disposición o digitación de cualquier acorde o escala que seleccionemos, o recursos para la improvisación que muestran las relaciones o posibilidades de uso de unos u otros en un determinado contexto armónico o tonal.

Por otra parte, es posible asociar archivos de audio o video a un texto musical de manera independiente o a varios de forma conjunta. En cualquier caso se posibilitan actividades la lectura comentada, es decir la posibilidad de leer el texto musical al tiempo que se escucha una determinada grabación previamente seleccionada del mismo y guardada en la memoria del dispositivo. De igual manera se permite la vinculación de backing tracks o pistas de acompañamiento que permiten su uso para el estudio o la improvisación al tiempo que podemos leer el texto con el cual se relacionan.

La incorporación de archivos de video permite, de la misma forma, su uso pedagógico como recurso para la enseñanza o el aprendizaje, pudiendo asociarse determinadas explicaciones o tutoriales, a determinadas obras o pasajes de especial dificultad o complejidad dentro de las mismas.

\subsection{Paso de página y opciones de vista}

Aunque la mayoría de las aplicaciones disponen de forma genérica de un gran número de posibilidades relacionadas con la configuración de página y las opciones de vista, (ampliamente desarrolladas en la aplicaciones de lectura literaria), quizás las más significativas en el ámbito de la lectura musical 
sean las que han surgido para solventar un problema muy común a la mayoría de los músicos, indistintamente de su contexto particular; nos referimos en este caso al paso de página. Los sistemas actuales permiten configurar una serie de herramientas y dispositivos periféricos para posibilitar el paso de página de manera sincronizada con la lectura sin tener que utilizar las manos que actúan sobre el instrumento que se ejecuta. En la actualidad son muchos los sistemas y las soluciones implementadas, y podemos afirmar que prácticamente existe una solución para cada necesidad específica. Al margen de las particularidades que cada una de ellas incorpora, todas permiten de alguna u otra manera la eliminación de zonas muertas, de manera que el texto que va a ser leído está presente en la pantalla momentos antes de que la vista recorra ese espacio.

\subsection{Herramientas y funciones básicas}

Independientemente de las funciones y soluciones específicas que las distintas aplicaciones incorporan en relación con su ámbito de aplicación o en función de la problemática específica inherente a los distintos tipos de instrumentos, o de los estilos musicales a los cuales sirven, la mayoría de las aplicaciones incorporan sistemáticamente un conjunto más o menos homogéneos de funciones y herramientas que de alguna forma cubren las necesidades más básicas que surgen de la lectura, estudio o interpretación para cualquier músico y en cualquier situación (Sung, 2013). Por un lado podemos encontrar teclados y pianos virtuales, con bancos de sonidos asociados que permiten reproducir de manera rápida y sencilla fragmentos del texto musical con el fin de obtener una primera recreación sonora real de la parte o fragmento deseado; además, representa un recurso muy útil en relación con trabajos como la composición o los arreglos musicales.

Por otra parte se incluye de manera casi universalizada algún tipo de metrónomo configurable que al margen de uso más genérico en contextos de estudio o aprendizaje ofrece, de igual manera, funciones de sincronización con los sistemas y herramientas de paso de página.

\section{Desarrollo de soluciones para problemas específicos. Paso de página}

Exceptuado las obras musicales de carácter vocal, en las que el uso de las manos no constituye un hándicap relevante, en la mayoría de los casos, el resto de composiciones que de carácter instrumental, conllevan a la hora de la ejecución (lectura) el problema (aún no resuelto) del paso de página. La necesidad de pasar la página de forma reiterada durante la recreación de una obra no solo implica necesariamente el tener que emplear por un momento, más o menos extenso, una de las manos que ejecutan sobre el instrumento para realizar una acción, que nada tiene que ver con 
la misma. Este detalle, que aparentemente puede parecer menor, es de vital importancia, por ciertas consideraciones.

Apartar una de las manos del instrumento no solo supone cortar el normal discurrir del discurso musical a nivel de ejecución sobre el instrumento, sino que condiciona emocionalmente y a nivel artístico la concentración y el desempeño del interprete. Este es un hecho incuestionable, en torno al cual no existen discrepancias relevantes en la comunidad musical, de hecho se da por asumido y como algo consustancial al hecho de la lectura musical; evidentemente este problema se presenta únicamente en relación a los intérpretes que actúan y ejecutan leyendo la obra. Fuera de estas consideraciones quedan, por lo tanto, todas las tipologías musicales y formas de recreación que o bien no contemplan en sus representaciones más comunes la interpretación con el texto musical, o las que directamente no precisan de un texto previamente creado (la mayoría de las veces basta con las mínimas indicaciones en torno a la progresión armónica o la melodía del tema); entre estas encontramos la mayoría de las músicas basadas en la improvisación. De modo ilustrativo se puede concluir que este problema es mucho más generalizado y acusado en la música clásica, y especialmente en los géneros denominados como sinfónicos y de cámara, y de forma general, en todos aquellos en los que el intérprete necesita una coordinación y sincronización cuasi matemática con el resto de intérpretes; en este sentido únicamente una ejecución con el texto musical presente garantiza el éxito en la recreación.

Existe un tercer grupo en el que se circunscriben todos aquellos solistas (pianistas, guitarristas, violinistas, etc.), que por una gran variedad de motivos (extensión del texto, dificultad a nivel formal del mismo, o simplemente como elección personal) optan por leer el texto musical en sus interpretaciones en público. Muchas veces la presencia del texto obedece a la necesidad de desarrollar la ejecución musical mediante la lectura del mismo, y otras, simplemente, para incorporarlo como guía o material de apoyo en pasajes o fragmentos especialmente complicados o difíciles de recordar (lectura como guía). En la mayoría de los casos, la forma y manera de plantear la ejecución musical en un contexto u otro obedecen casi en exclusiva a cuestiones de carácter personal como los métodos de estudio, la mayor o menor facilidad para recordar las obras, o por otras más subjetivas como la sensación de seguridad y confianza. En muchos de los casos resulta relativamente frecuente encontrarnos con solistas (normalmente pianistas) que actúan de manera sistemática y como norma con una persona a su lado que se encarga del paso de página. Esta situación implica de manera necesaria que ambos deben formar un equipo en el que la confianza y el conocimiento previo resultan imprescindibles.

Los nuevos sistemas de paso de página incorporados a los dispositivos de lectura electrónica, solucionan de manera sencilla y eficaz todos los problemas anteriormente señalados; estos, y algunos más. Al margen del resto de inconvenientes y casuística relacionada, es necesario señalar 
que inclusos cuando el paso de página en textos en papel se soluciona mediante una persona convenientemente entrenada y dedicada a estas tareas, la propia disposición de los textos en este soporte conlleva la creación de espacios muertos de lectura, conforme se realiza el paso de página. En este sentido el acceso visual al texto en los últimos compases al final de página y los primeros de la página siguiente, resulta deficiente, o al menos, no en las misma condiciones que en el resto de compases cuando el paso de página no se efectúa.

El paso de página en partituras electrónicas, se ha resuelto mediante el desarrollo diferentes métodos que integran soluciones efectivas a toda la serie de problemas que concurren en el paso de página en textos en papel.

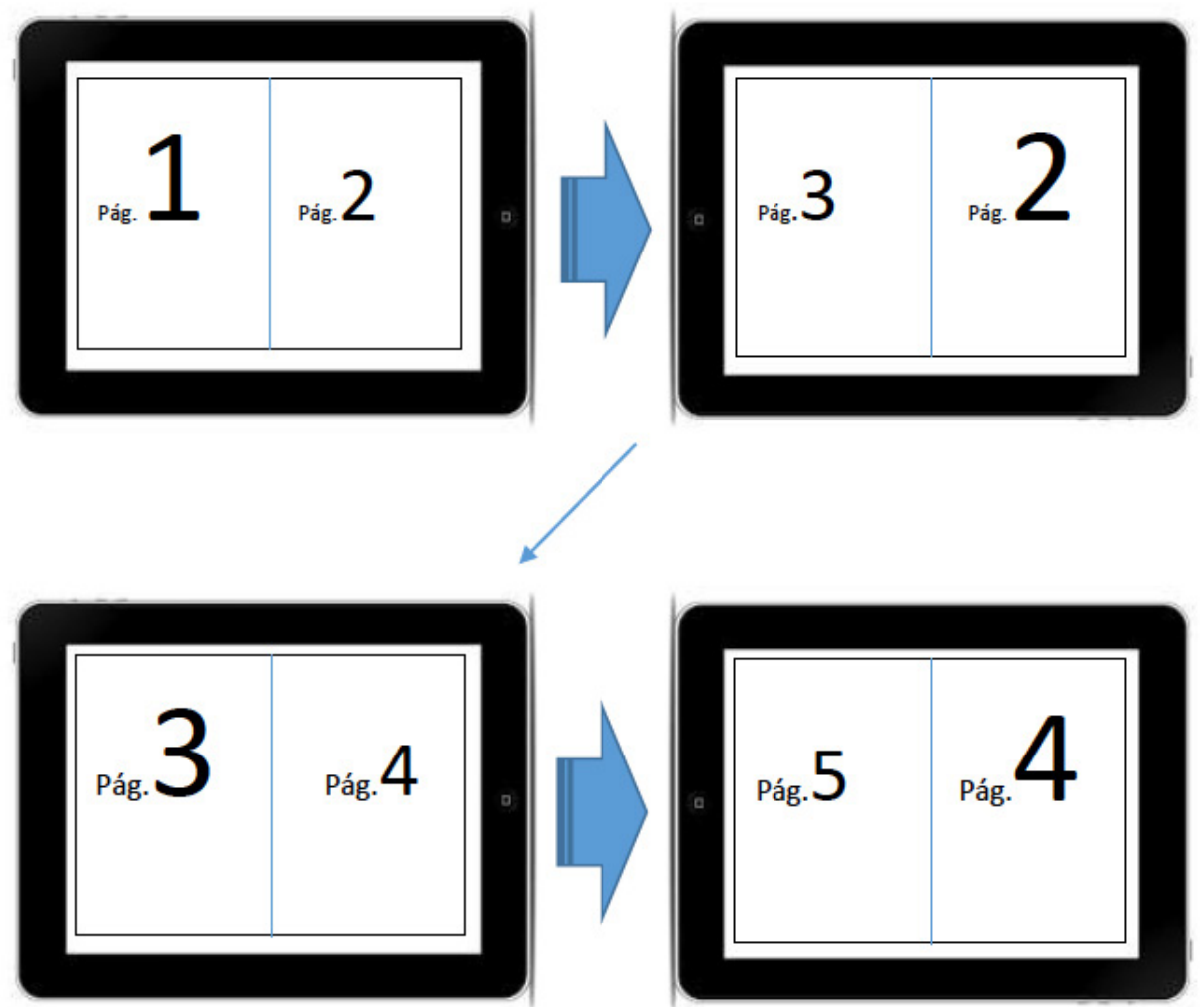

Figura 4. Sistema de paso de página para evitar zonas muertas, en disposición horizontal 6 . Fuente: Elaboración propia. 


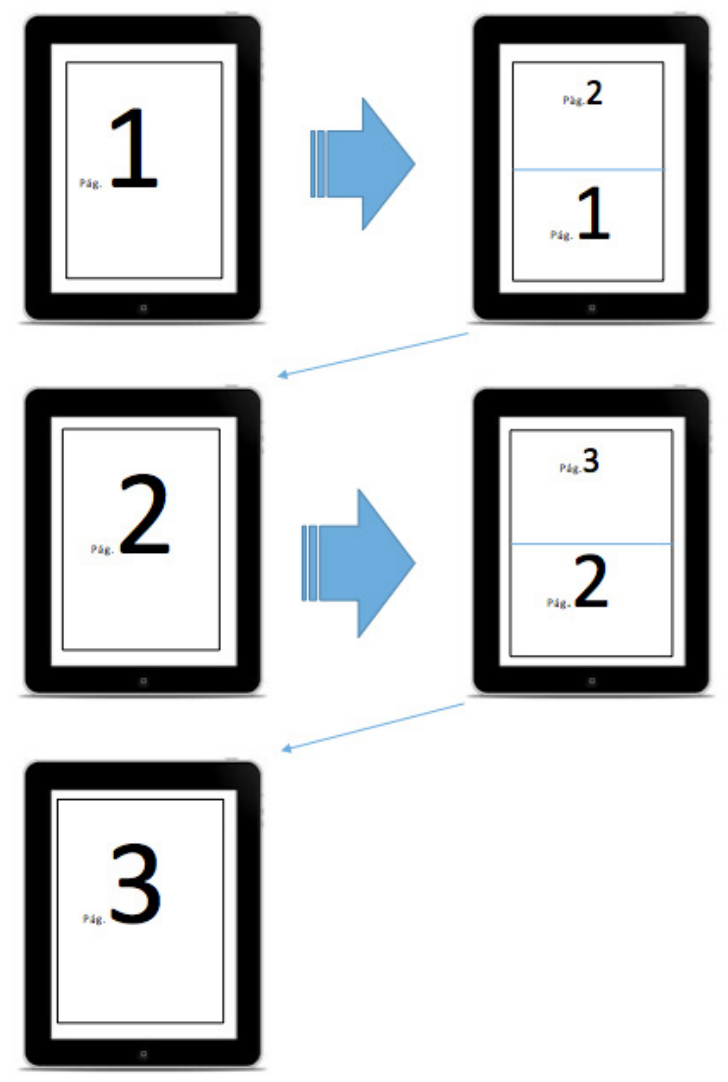

Figura 5. Sistema de paso de página para evitar zonas muertas, en disposición horizontal. Fuente: Elaboración propia.

\subsection{Sistemas de paso de página a nivel operativo}

Al margen del sistema implementado para desarrollar el paso de página a nivel de la disposición textual, es necesario establecer mecanismos precisos que permitan sincronizar de una manera u otra el modo y el momento en el que este se produce. Actualmente son tres los métodos y sistemas más extendidos y aceptados por la comunidad musical, cada uno de ellos con sus ventajas y con sus inconvenientes;

- Sistemas de paso de página por sincronización en el tiempo.

- Sistemas de paso de página mediante dispositivos externos vía Bluetooth.

- Sistemas de paso de página gestual.

No obstante, y aunque la elección de cada uno de ellos depende del contexto de uso o de la casuística particular, los sistemas disponibles en la actualidad cubren casi por completo cualquier necesidad especifica que pueda presentarse.

\subsubsection{Sistemas de paso de página por sincronización en el tiempo}

Los sistemas basados en la sincronización mediante pulso o tempo establecen mecanismos automatizados de sincronización respecto al paso de página mediante la asignación al texto musical 
de un número de compases concretos (esta tarea debe realizarse de manera manual, excepto en formatos propietarios), y la contabilización de los mismos en referencia a un tempo establecido o elegido por el intérprete. Este proceso básicamente consiste en el que el dispositivo reconoce los compases que cada página incorpora, el número de pulsos o partes de cada compas y la velocidad (tempo, Bpm ) en la que trascurren; de esta manera la aplicación va contando pulsos o beats, (y subsidiariamente compases) y cuando reconoce el ultimo de cada página procede a pasar a la siguiente.

\subsubsection{Sistemas de paso de página mediante dispositivos externos vía Bluetooth}

Este es, sin lugar a dudas, el sistema más desarrollado, aceptado y funcional de entre todos los disponibles a día de hoy. Permite el control total de las funciones relacionadas con el paso de página de una forma sencilla, fiable e intuitiva, consistente en el accionamiento con el pie de un conmutador que envía la señal que indica el paso de página al dispositivo; en contraprestación, únicamente es necesario un cierto nivel de entrenamiento y familiarización con el dispositivo externo que lo gobierna (Wolberg \& Schipper, 2012).

La posibilidad de poder acceder a la página deseada, en el momento deseado, de manera independiente a si esta se encuentra en un dirección u otra (adelante o atrás), posibilita la reproducción de cualquier tipo de texto musical, de manera independiente a sus estructura o su organización; siendo estos muy adecuados para la ejecución musical en textos editados a la manera tradicional, o simplemente escaneados de obras editadas en papel; indistintamente de la edición, el instrumento, o la estructura formal que presenten. Se posibilita en este sentido una flexibilidad total para interactuar con cualquier tipo de contenido, independientemente del formato y la disposición del mismo.

No obstante, se han desarrollado, de manera paralela, otros dispositivos con el mismo esquema general de funcionamiento, pero que permiten el control del sistema de manera adecuada en entornos más dinámicos donde existen multitud de agentes en movimiento y todo tipo de vibraciones; nos referimos principalmente a situaciones de directo de bandas y grupos de música moderna donde el ruido mecánico no incide en la percepción del mensaje musical, y donde al contrario que en las situaciones anteriormente referidas, prevalece la robustez y la fiabilidad sobre la sensibilidad y la discreción.

Como en cualquiera de los casos, estas soluciones cuentan con apenas unos años de desarrollo, no es desdeñable contemplar que en un futuro cercano la constante demanda de nuevas soluciones relacionadas con entornos y casuísticas concretas permitan el desarrollo de nuevas soluciones que tengan un marcado carácter de especialización a las características que se requieran. 


\subsubsection{Sistemas de paso de página gestual}

Con la idea de posibilitar la incorporación de los sistemas de paso de página a todos los requerimientos posibles y, sobre todo, a todo tipo de intérpretes, en los últimos años se han desarrollado accesorios y mecanismos que adaptan los esquemas generales incorporados en los dispositivos externos vía Bluetooth para todas aquellas situaciones en las que el uso de ambas manos o pies están implicados en la ejecución musical. En este grupo se incluyen sobre todo a los organistas y bateristas. En el primer caso la adaptación de estos sistemas es absolutamente necesaria e imprescindible porque, de una parte, el uso de los pies en este instrumento es tan relevante o más que el uso de las manos, y por otra, porque la inmensa mayoría de los músicos especialistas en el instrumento y en sus repertorio ejecutan las obras mediante la lectura sincrónica de la misma. La complejidad de la estructura armónica y contrapuntística, unido al gran número de voces que intervienen, así lo hacen necesario. Por todo ello es de gran utilidad para estos músicos contar con sistemas que adapten el paso de página mediante dispositivos externos y que a la vez, no implique uso de los pies o manos para tal efecto.

Las soluciones aplicadas que se han mostrado como fiables y operativas incluyen una serie de accesorios que permiten traducir diferentes gestos y movimientos (generalmente de la cara o la boca) en señales que impliquen en paso de página en uno u otro sentido.

\section{Referencias Bibliográficas}

Brodsky, W., Kessler, Y., Rubinstein, B.-S., Ginsborg, J., \& Henik, A. (2008). The mental representation of music notation: notational audiation. Journal of Experimental Psychology. Human Perception and Performance, 34(2), 427-45. doi:http://doi.org/10.1037/0096-1523.34.2.427

Galera, M., \& Gim, T. (2012). Lectura musical y procesos cognitivos implicados Music reading: some of its cognitive processes. LEEME.Revista Electrónica Europea de Música En La Educación, 29(29), $56-82$.

Gould, E. (2011). Behind Bars: the Definitive Guide to Music Notation (1st ed., p. 704). Faber Music Ltd.

Gudmundsdottir, H. R. (2010). Advances in Music Reading Research Helga Rut Gudmundsdottir, (June 2009), 1-16.

Read, G. (1982). Music notation : a manual of modern practice. (V. Gollanz, Ed.) (p. 482). London. 
Schön, D., \& Besson, M. (2002). Processing pitch and duration in music reading: a RT-ERP study. Neuropsychologia, 40(7), 868-78. doi:http://dx.doi.org/10.1016/S0028-3932(01)00170-1

Sloboda, J. A. (2005). Exploring the Musical Mind: Cognition, Emotion, Ability, Function (primera). Oxford: Oxford university Press.

Sung, H. (2013). From Paper to Pixels - Your Guide to the Digital Sheet Music Revolution. (J. Townsend, Ed.) (p. 368). KaSu Press (July 7, 2013).

Tonazzi, B. (1996). Liuto, vihuela, chitarra e strumenti similari nelle loro intavolature.con cenni sulle lor letterature (terza ediz, p. 176). Ancona, Italia: Bérben Edizioni Musicali.

Waters, A. J., Underwood, G., \& Findlay, J. M. (1997). Studying expertise in music reading: use of a pattern-matching paradigm. Perception \& Psychophysics, 59(4), 477-88. doi:http://dx.doi.org/10.3758/ BF03211857

Wolberg, G., \& Schipper, I. (2012). Page turning solutions for musicians: a survey. Work (Reading, Mass.), 41(1), 37-52. doi:http://doi.org/10.3233/WOR-2012-1242 